\title{
Pretrial Bargaining and the Design of Fee-Shifting Rules
}

\section{Citation}

Kathryn E. Spier, Pretrial Bargaining and the Design of Fee-Shifting Rules, 25 RAND J. Econ. 197 (1994).

\section{Published Version}

doi: $10.2307 / 2555827$

\section{Permanent link}

http://nrs.harvard.edu/urn-3:HUL.InstRepos:12187120

\section{Terms of Use}

This article was downloaded from Harvard University's DASH repository, and is made available under the terms and conditions applicable to Other Posted Material, as set forth at http:// nrs.harvard.edu/urn-3:HUL.InstRepos:dash.current.terms-of-use\#LAA

\section{Share Your Story}

The Harvard community has made this article openly available.

Please share how this access benefits you. Submit a story.

Accessibility 


\title{
Pretrial bargaining and the design of fee-shifting rules
}

\author{
Kathryn E. Spier*
}

Legal rules for allocating the private costs of civil litigation, or "fee-shifting" rules, provide powerful incentives for settlement. Within the context of a direct-revelation mechanism, the fee-shifting rule that generates the highest probability of settlement bases the allocation of costs upon the proximity of the court's award to the pretrial announcements. This mechanism resembles Rule 68 of the Federal Rules of Civil Procedure and other offerbased rules. In a simple extensive-form game, if the litigants have asymmetric information about the level of damages (probability of prevailing), then Rule 68 increases (decreases) the settlement rate.

\section{Introduction}

- This article analyzes legal rules for allocating the private costs of civil litigation between a plaintiff and a defendant. In Europe and England, the loser is typically forced to bear the winner's legal expenses (the English Rule), while in the United States, each litigant traditionally bears his own costs (the American Rule). ${ }^{1}$ Many statutes on the state and federal levels, however, provide for the shifting of fees under particular circumstances. Some of these rules resemble the English system for allocating costs. Another interesting class of rules bases the allocation of costs upon the settlement offers made before the trial: If a litigant rejects a settlement offer prior to the trial and later receives a less favorable judgement at trial, then he must compensate his opponent for certain costs incurred after the offer was made. ${ }^{2}$ The most notable offer-based fee-shifting rule is Rule 68 of the Federal Rules of Civil Procedure. ${ }^{3}$

* Northwestern University.

I would like to thank Aaron Edlin, James Dana, Oliver Hart, Keith Hylton, Louis Kaplow, Lewis Kornhauser, Daniel Kessler, Ivan Png, A. Mitchell Polinsky, Jennifer Reinganum, George Shepherd, the referees, and seminar audiences at Stanford and Yale Law Schools, and economics departments at MIT, Harvard, Northwestern, Rochester, Boston College, and the University of Pennsylvania for helpful comments and suggestions. All errors are, of course, my own. Financial support from the Olin Foundation is gratefully acknowledged.

${ }^{1}$ Leubsdorf (1984) presents a historical analysis of the American Rule. Rules for shifting the costs of litigation have existed for thousands of years; under early Roman law, for example, each party contributed money to an account, and the winner was refunded his deposit at the trial's conclusion. Pfennigstorf (1984) discusses the origins of the English Rule and current European practices.

${ }^{2}$ Notice that this class of rules contrasts nicely with the English Rule, because "winning" and "losing" are not absolute in nature but are relative to the offers and demands of the litigants before the trial.

${ }^{3}$ Rule 68 reads: "At any time more than 10 days before the trial begins, a party defending against a claim may serve upon the adverse party an offer to allow judgment to be taken against him for the money or property or to the effect specified in his offer, with costs then accrued. . . . If the judgment finally obtained by the offeree is not more favorable than the offer, the offeree must pay the costs incurred after the making of the offer." 
This article shows that if the litigants are asymmetrically informed about the merits of the case, then fee-shifting rules that are based upon the settlement offers made before the trial have powerful incentive properties. First, I explore the impact of Rule 68 on settlement behavior in a simple extensive-form bargaining game and show that when the litigants disagree about the level of damages, this rule tends to increase the settlement rate. (If, on the other hand, they disagree about liability or the probability of prevailing, then Rule 68 tends to decrease the settlement rate.) Next, I consider the class of directrevelation mechanisms and jointly characterize the pretrial bargaining game and the feeshifting rule that lead to the highest probability of settlement. ${ }^{4}$ The rule that emerges is strikingly similar to statutes where either litigant may be penalized for rejecting a more favorable offer prior to the trial.

In the mechanism-design framework, the settlement rate is highest when the court uses the information it receives from the settlement negotiations to generate a cutoff for its own findings. If the court's later assessment of the damages is above this cutoff, then the defendant bears all of the costs of litigation. If the court's assessment of damages is below the cutoff, then the plaintiff bears all of the costs. The intuition is straightforward: When asymmetric information hinders settlement, fee shifting facilitates the credible transmission of information between the litigants, which in turn increases the likelihood of settlement. The plaintiff, for example, is deterred from making excessive demands prior to the trial, for he may have to pay the defendant's costs if the case proceeds to court. If the court's damage assessment is low relative to the plaintiff's claims, then the court will behave as if the plaintiff had been exaggerating or lying and fine him accordingly. In this way, the litigants are given the incentive to negotiate in good faith prior to the trial. ${ }^{5}$

Actual offer-based fee-shifting rules exhibit some, but not all, of the properties of this abstract mechanism. Rule 68, for example, is one-sided: The plaintiff can be forced to bear the defendant's costs but not vice versa. Despite its prodefendant nature, the most commonly cited purpose of Rule 68 is to encourage settlement: "The nearly 100 Rules of Federal Civil Procedure have numerous and often differing purposes, but it bears repeating that the purpose behind Rule $68, \ldots$, is to promote settlement and thereby diminish the number of trials necessary to resolve the cases which are filed in the federal courts." ${ }^{6}$ In practice, however, this rule has been viewed as largely ineffective in encouraging settlement, primarily because the "costs" in Rule 68 do not automatically include attorneys' fees. ${ }^{7}$ Recent proposals to amend the Federal rules recognize this and recommend that the definition of costs be broadened and that the rule be extended to offers made by the plaintiff. ${ }^{8}$ In 1985, the Supreme Court's decision in Marek v. Chesny extended the definition

${ }^{4}$ Although administrative efficiency is of great concern to policy makers, reducing the litigation rate is only one of many goals of the legal system. The plaintiff's incentive to bring suit, the defendant's ex ante incentives, and fairness are important as well, but a full analysis of these issues is beyond the scope of this article. It should be noted that since judges are central in the creation and amending of the Federal rules, these rules may be biased in favor of judges. In particular, the rules may be designed, at least in part, to either lighten the workload of judges or select for interesting cases (Macey, 1994).

${ }^{5}$ This fee-shifting rule creates countervailing incentives for the litigants (see, e.g., Lewis and Sappington (1989)). We will see that a player has an incentive to overstate his type for the purpose of bargaining with his opponent, while he has an incentive to understate his type for the purpose of fee shifting. Here, as in the literature, the creation of these countervailing incentives increases efficiency.

${ }^{6}$ Delta Air Lines, Inc. v. August, 450 U.S. 346, 379 (1981). The court also stated that “. . .parties to litigation and the public as a whole have an interest_often an overriding one-in settlement rather than the exhaustion of protracted court proceedings. Rule 68 makes available to defendants a mechanism to encourage plaintiffs to settle burdensome lawsuits." Delta Air Lines, Inc. v. August, 450 U.S. 346, 363 (1981).

${ }^{7}$ Note that even when attorneys' fees are not included in the definition of costs, other allowable costs such as expert-witness fees may be sizable.

${ }^{8}$ Preliminary Draft of Proposed Amendments to the Federal Rules of Civil Procedure, 98 Federal Rules Decisions 337 (1983). This proposal and its revision, 102 F.R.D. 407 (1984) met with criticism and have not been enacted (see Simon (1985)). More recently, the Advisory Committee on the Civil Rules has been considering new proposals. See, for example, the discussion in Schwarzer (1992). 
of costs in civil rights cases to include attorneys' fees for the purpose of Rule 68 offers. ${ }^{9}$

There are many other examples of offer-based fee-shifting statutes in the United States. ${ }^{10}$

On the state level, for example, California Code of Civil Procedure Rule 998 provides for the two-sided shifting of costs, although it does not currently extend the definition of costs to include attorneys' fees. Also, many state courts determine the award of interest on the plaintiff's damages (prejudgment interest) using a similar scheme. If a plaintiff rejects a "reasonable" offer, then he may not be entitled to the interest on his claim accruing from the time of the offer (Carroll, 1983). ${ }^{11}$ Over the past several years, Congress has considered legislation to reform the product liability system; recently, one piece of proposed legislation included a powerful offer-based fee-shifting rule designed to reduce the level of litigation. This rule was two-sided (applying to offers made by either party), included attorneys' fees in its definition of costs, and raised the stakes for the litigants by requiring that their relevant offers be made within 60 days of filing suit. ${ }^{12}$

Many economists and legal scholars have analyzed the consequences of simple feeshifting rules using the nonstrategic model pioneered by Landes (1971), Posner (1973), and Gould (1973). ${ }^{13}$ In this approach, the litigants have subjective beliefs about the likelihood of prevailing in court and the magnitude of the award. Shavell (1982) showed that (under certain assumptions) a shift from the American Rule to the English Rule leads to fewer out of court settlements. When the litigants are mutually optimistic about the probability of prevailing, then a shift to the British system decreases the parties' subjective assessments of their expected costs, and hence settlement becomes less likely. ${ }^{14}$ Miller (1986) argued that the main effect of Rule 68 is to make the outcome more favorable to the defendant, while the effect on the settlement rate is ambiguous.

More recent theoretical analyses have explicitly modelled the asymmetric information and have allowed the litigants to behave strategically. Using a game-theoretic approach with one-sided incomplete information about the probability of winning, Bebchuk (1984) showed that when the uninformed player makes a single offer, the English Rule will decrease the likelihood of settlement. ${ }^{15}$ When liability is in dispute, the English Rule tends to exaggerate the effect of asymmetric information by making strong cases stronger and weak cases even weaker. In a model where the informed player makes a final offer, Reinganum and Wilde (1986) demonstrated that if the probability of winning is common knowledge, then the English and American Rules lead to precisely the same amount of settlement. $^{16}$

All of these previous studies of fee-shifting rules have restricted attention to relatively simple extensive-form bargaining games and (with the exception of Miller (1986)) have focused upon the American and English Rules. This article, on the other hand, analyzes

\footnotetext{
${ }^{9}$ More generally, the court argued that ". . . where the underlying statute defines 'costs' to include attorney's fees, we are satisfied such fees are to be included as costs for purposes of Rule 68." 105 S.Ct. 3012, 3016 (1985).

${ }^{10}$ The English "payment-into-court rule" also falls into this class (Schwarzer, 1992).

${ }^{11}$ On a related note, many districts have experimented with fee shifting as a means to strengthen the effectiveness of court-annexed arbitration. Typically, if a litigant rejects the arbitrator's decision and then opts for a trial, then fees may be shifted if the judgement at trial is not sufficiently favorable (Bernstein, 1993).

${ }^{12}$ Senate Bill 640, March 13, 1991, Congressional Record, p. S-3255.

${ }^{13}$ Empirical work on the topic is still in its infancy, but see Snyder and Hughes (1990) and Fournier and Zuehlke (1989).

${ }^{14}$ This is not necessarily true when the costs are endogenous; see Braeutigam, Owen, and Panzar (1984), Katz (1987), and Hause (1989).

${ }^{15}$ Cooter, Marks, and Mnookin (1982) have a similar result.

${ }^{16}$ Although they are not concerned with fee-shifting rules, Daughety and Reinganum (1991) analyze the admissibility of settlement offers as evidence at trial using an extensive-form game. They show that the plaintiff has an incentive to demand too high an amount in settlement, because it serves as a valuable signal to the court that damages are high. Consequently, the settlement rate falls. Here, however, the plaintiff will tend to soften a demand to avoid the shifted fees, and the settlement rate rises.
} 
rules which may be sensitive to the pretrial activity and constructs the rule that maximizes the probability of settlement. In this way, the rule that achieves a Pareto frontier for the bargaining game is characterized. Despite its abstraction, the mechanism-design approach generates clear and intuitively appealing results about settlement behavior and produces a realistic fee-shifting rule that is effective in a variety of bargaining specifications.

In the next section I describe the model and its assumptions. In the third section I explore the impact of Rule 68 in a well-known screening model. The fourth section establishes a general inefficiency result and jointly characterizes the fee-shifting rule and bargaining game that form the efficiency frontier. Concluding remarks follow.

\section{The model}

Suppose a plaintiff and a defendant are negotiating prior to a costly trial. They are risk-neutral and each possesses private information about the future behavior of the court. The plaintiff, for example, may have first-hand information about the value of his damages, and the defendant may have better knowledge of the extent of his liability or degree of negligence. The plaintiff's private information, denoted by $x$, is drawn from a probability density function, $f_{X}(x)$, which is strictly positive on the support $[\underline{x}, \bar{x}]$ and zero elsewhere. Similarly, the defendant's private information, $y$, is drawn from $f_{Y}(y)$ on the support [ $y, \bar{y}] . F_{X}(x)$ and $F_{Y}(y)$ denote the cumulative distribution functions. If the parties go to trial, the court will observe a signal, $z$, which is drawn from the density function $h(z \mid x, y)$, and the litigants will incur private costs $k_{P}$ and $k_{D}$ (let $K=k_{P}+k_{D}$ ). The signal $z$ is interpreted as the level of damages and penalties (net of legal costs) for which the defendant is liable. If the case is litigated, we suppose that the court must enforce a transfer of $z$ from the defendant to the plaintiff and allocate the litigants' costs according to a prespecified fee-shifting rule. ${ }^{17}$

If the parties have symmetric information concerning the trial's outcome, then the negotiations are likely to succeed in resolving the dispute. There may be many offers and counteroffers, but if one of the litigants has the opportunity to make a final offer, then the parties (being rational and symmetrically informed) will settle rather than proceed to court. Asymmetric information, however, may seriously impede the pretrial negotiation process. If the parties reach the final stage of bargaining in which one party makes a final offer, then typically some types will proceed to trial (Bebchuk, 1984; Reinganum and Wilde, 1986; and Nalebuff, 1987). Perhaps surprisingly, extending the game to include many periods of bargaining does not change this result (Spier, 1992a). Since these models feature common values, when litigation costs are sufficiently small, there will not exist a game in which asymmetrically informed parties always settle their dispute (Spulber, 1990; Spier, 1989; and Schweitzer, 1989). The following sections build upon this literature by illustrating how offer-based fee-shifting rules can facilitate informational exchange during negotiations and thereby increase the likelihood of settlement.

\section{The effect of Rule 68 in a screening game}

In this section I analyze a simple sequential game with one-sided incomplete information. The defendant's type, $y$, is assumed to be common knowledge. The plaintiff privately observes the strength of his case, $x$, and the court's award, $z$, is such that $E(z \mid x)=x$ (so higher $x$ 's are more favorable to the plaintiff). Assuming that $\underline{x}-k_{P} \geq 0$ guarantees that the plaintiff would never want to drop the case. The uninformed defendant makes a

${ }^{17}$ The award, $z$, is not a choice variable for the court. This is consistent with Rule 68 , which states that "an offer not accepted shall be deemed withdrawn and evidence thereof is not admissible except in a proceeding to determine costs." Moreover, Evidence Rules 408 and 409 deem settlement offers inadmissible in proving liability or determining damages. A theoretical justification for these rules is given in Daughety and Reinganum (1991). 
single offer to the plaintiff prior to the trial, which the plaintiff can either accept or reject. The structure of this game is similar to Bebchuk (1984) but considers a more general technology and a more elaborate fee-shifting rule. The implications discussed in this section also hold when the defendant has private information and makes a take-it-or-leave-it offer to the uninformed plaintiff (see Spier (1992b)).

Under the American Rule, the plaintiff accepts an offer, $s$, if and only if it exceeds what he expects to receive in court minus his costs, or $s \geq x-k_{P}$. There is a one-to-one correspondence between the defendant's offer and the cutoff for the plaintiff's type: $x(s)=s+k_{P}$. Therefore, we can write the defendant's expected payment as a function of the settlement offer, $s$, as follows:

$$
F(x(s)) s+\int_{x(s)}^{\bar{x}}\left[t+k_{D}\right] f_{X}(t) d t .
$$

The first term reflects that a plaintiff with a low expected award will accept the offer; the second term reflects that a plaintiff with a high expected award will reject the offer, forcing the defendant to incur $k_{D}$ in court. Setting the derivative of this expression equal to zero (and assuming an interior solution) gives us the defendant's optimal offer, $s^{A R}$, and the corresponding cutoff, $x^{A R}=x\left(s^{A R}\right)$. The equilibrium settlement rate $F_{X}\left(x^{A R}\right)$ is implicitly defined by the first-order condition

$$
\left(k_{P}+k_{D}\right) f_{X}\left(x^{A R}\right)-F_{X}\left(x^{A R}\right)=0 .
$$

This expression may be understood intuitively. The benefit to the defendant from raising his offer is reflected in the first term: The likelihood of acceptance increases, and on the margin the defendant saves his cost, $k_{D}$, and is able to extract $k_{P}$ from the plaintiff. The second term reflects the corresponding cost: By raising the offer, the defendant pays more to those types who accept the offer.

Under Rule 68, the equilibrium offer serves as a cutoff for the allocation of costs. (We will assume here that the costs under this rule include all postoffer expenses.) If the court's award, $z$, is below the offer, then the plaintiff pays the defendant's costs; if $z$ is above the offer, then the defendant pays his own costs. The plaintiff accepts $s$ if and only if $s \geq x-k_{P}-k_{D} H(s \mid x)$. As before, this expression implicitly defines a correspondence between the offer and the cutoff for the plaintiff's type. Let $x(s)$ denote this implicit function. Totally differentiating the definition of $x(s)$ gives us that $d x(s) / d s$ is (implicitly) given by

$$
\frac{d x(s)}{d s}=\frac{1+k_{D} h(s \mid x)}{1-k_{D} \frac{\partial H(s \mid x)}{\partial x}}
$$

Proceeding as before, we may express the defendant's expected payment as

$$
F(x(s)) s+\int_{x(s)}^{\bar{x}}\left\{t+[1-H(s \mid t)] k_{D}\right\} f_{X}(t) d t .
$$

Differentiating this expression (and assuming an interior solution) gives us the defendant's optimal Rule 68 offer, $s^{68}$, and the corresponding cutoff, $x^{68}=x\left(s^{68}\right)$, as the solution to the following first-order condition:

$$
\left(k_{P}+k_{D}\right) \frac{d x\left(s^{68}\right)}{d s} f_{X}\left(x^{68}\right)-F_{X}\left(x^{68}\right)+k_{D} \int_{x^{68}}^{\bar{x}} h(s \mid x) f_{X}(x) d x=0 .
$$

As before, the first term reflects the defendant's benefit from inducing more settlement through a higher offer, and the second is the increased payment to those who accept the 
offer. The third term, however, represents an additional benefit to the defendant: The plaintiff types who opt for a trial are more likely to bear the defendant's costs. By increasing his offer, the defendant both reduces the probability of a trial and reduces his expected cost contingent upon reaching trial.

Comparing (2) and (5), we find that if the inverse hazard rate is monotonic, i.e., $F_{X}(x) / f_{X}(x)$ is increasing in $x$, then $d x(s) / d s \geq 1$ is a weak sufficient condition for $x^{68}$ to be greater than $x^{A R}$, or equivalently, for Rule 68 to increase the settlement rate.

Example 1. Suppose that $x$ shifts the mean of $h(z \mid x)$ without changing other characteristics of the distribution. Then, $\partial H(s \mid x) / \partial x=-h(s \mid x)$, and from (3), we have $d x(s) / d s=1$. Hence, comparing (2) and (5), we see that Rule 68 increases the probability of settlement.

Example 2. Suppose that $z$ is binary: The plaintiff will either recover damages $D$ ("win") or get nothing ("lose"). Since $x$ was assumed to be the expected award, the probability that the plaintiff will win the case is given by $x / D$. Since by assumption $\underline{x}-k_{P} \geq 0$, the settlement offer will never be negative. Therefore, the probability that the plaintiff will pay the defendant's costs is independent of the offer and is given by $1-x / D .{ }^{18}$ From (3), we have $d x(s) / d s=1 /\left(1+k_{D} / D\right)<1$, and the third term in (5) is zero. Intuitively, the third effect described above for (5) has no power: A small change in the settlement offer does not effect the probability that $z$ will fall below the offer. Thus, Rule 68 decreases the probability of settlement. ${ }^{19}$

These two examples suggest the following: If the litigants disagree about damages but liability is acknowledged, then Rule 68 tends to increase the likelihood of settlement. If the litigants disagree about liability and damages are known, however, then Rule 68 tends to decrease the likelihood of settlement. Interestingly, this theoretical insight is consistent with the Supreme Court's decision in Delta Air Lines, Inc. v. August. ${ }^{20}$ While a prevailing plaintiff whose judgement is less favorable than the Rule 68 offer is responsible for the defendant's costs, the court held that Rule 68 does not apply to cases in which the plaintiff loses altogether. The court argued that this reflects the original purpose of the rule and stated that "Rule 68 provides an additional inducement to settle in those cases in which there is a strong probability that the plaintiff will obtain a judgement but the amount of recovery is uncertain."

Finally, the prodefendant nature of Rule 68 clearly implies that the defendant's monetary loss from being sued is smaller, and therefore he has less of an incentive to exercise care at the ex ante stage. Moreover, the plaintiff has less of an incentive to bring suit, since his return falls relative to the American Rule. This indirect effect further reduces the defendant's level of care. The reduction in precaution taking would be undesirable if the penalty (the $z$ 's) were originally set at the socially optimal level; however, a simple rescaling of the penalty structure (through a multiplier on damages, perhaps) could restore incentives for care.

\section{Direct-revelation mechanisms}

- What type of fee-shifting rule will provide the litigants with the strongest incentives to settle their case out of court? To address this question, one might choose a particular extensive-form bargaining game and construct the fee-shifting rule that maximizes the probability of settlement. This approach would not be very fruitful, however. The rule

\footnotetext{
${ }^{18}$ When the plaintiff loses he pays the defendant's costs, but when the defendant loses, both the plaintiff and the defendant bear their own costs. Notice the similarity to the English Rule.

${ }^{19}$ This example may be viewed as a variation on Bebchuk's (1984) result for the English Rule. The intuition for the result is straightforward: When liability is in dispute, then fee shifting tends to exaggerate the asymmetric information, making strong plaintiffs stronger and weak ones even weaker.

${ }^{20} 450$ U.S. 346, 352 (1981).
} 
would be sensitive, first, to the timing of the game (there is no "correct" specification for the sequence of offers) and, second, to the structure of the asymmetric information. In the previous example, the rule would essentially enforce a particular offer and cutoff region by punishing the litigants if they deviated.

Instead of analyzing a particular sequential bargaining game, this section addresses these issues in a more abstract framework. To start, notice that each fee-shifting rule that the court could adopt corresponds to a least upper bound on the likelihood of settlement: Given the rule, every pretrial bargaining game will lead to a probability of settlement below this limit. In this section I use mechanism-design techniques to construct the feeshifting rule that establishes the highest limit for the settlement rate, or the Pareto frontier.

By the revelation principal (see Myerson (1979)), any Bayesian equilibrium of any sequential bargaining game may be achieved as a truth-telling equilibrium of a direct-revelation mechanism which maps the players' private information directly into outcomes. In our context, the litigants simultaneously make announcements of their "types," $\hat{x}$ and $\hat{y}$, and the mechanism maps these announcements into the vector $\left\langle p(\hat{x}, \hat{y}), S(\hat{x}, \hat{y}), C_{P}(\hat{x}, \hat{y}, z), C_{D}(\hat{x}, \hat{y}, z)\right\rangle$, which will be abbreviated $\langle p, S, C\rangle$. The first two instruments in this vector are independent of the court's signal and may be thought of as the pretrial components of the mechanism: $p(\hat{x}, \hat{y})$ is the probability that the case will proceed to trial, and $S(\hat{x}, \hat{y})$ is a transfer from the defendant to the plaintiff. $S(\hat{x}, \hat{y})$ is interpreted as the settlement amount, and without loss of generality, we restrict $S(\hat{x}, \hat{y})=0$ if the case goes to trial. ${ }^{21}$ The trial stage of the game is exogenously specified: The court observes its signal and awards $z . C_{P}(\hat{x}, \hat{y}, z)$ and $C_{D}(\hat{x}, \hat{y}, z)$ represent the feeshifting rule (or the costs borne by the plaintiff and defendant, respectively) and are interpreted as the post-trial components of the mechanism. These instruments may depend upon the court's signal as well as the pretrial announcements, are constrained to be nonnegative, and sum to $K{ }^{22}$ As mentioned earlier, the treatment of the court's award, $z$, as independent of the announcements while the fee-shifting rule may depend upon them is consistent with the Federal Rules of Evidence. ${ }^{23}$

When analyzing bargaining mechanisms, it is necessary to specify what happens in the event the parties refuse to participate. In other words, we need to specify "outside options" for the litigants. We assume that if a player opts out of the mechanism, then the case goes to trial and each litigant bears his own legal costs. The outside option payoffs for the plaintiff and defendant, respectively, are $E_{Y} E_{Z}\left[z-k_{P} \mid x, y\right]$ and $E_{X} E_{Z}\left[-z-k_{D} \mid x, y\right] .{ }^{24}$ This assumption is made in the spirit of Rule 68 , where if no offer is served by the defendant, then the American Rule is applied.

Within the class of direct-revelation games, we construct the mechanism that minimizes the ex ante sum of the expected costs borne by the two parties or, equivalently, maximizes the settlement rate. This mechanism jointly characterizes the bargaining game

${ }^{21}$ Alternatively, define $R(\hat{x}, \hat{y})=[1-p(\hat{x}, \hat{y})] S(\hat{x}, \hat{y})$ to be a transfer that is independent of whether the case goes to trial. None of the results would change, but the transfer would lack a clear interpretation. Note that if the transfer could depend upon the court's signal, then the mechanism could easily induce all cases to settle out of court.

${ }^{22}$ The settlement rate would increase even further if amounts in excess of the actual costs could be shifted. So long as the litigants are liquidity constrained, however, the optimal mechanism will exhibit the same qualitative features.

${ }^{23}$ In Hopper v. Euclid Manor Nursing Home, Inc. (867 F.2d 291, 6th Cir. 1989), the district judge (apparently unaware that a Rule 68 offer had been served) awarded the plaintiff less than the offer made before the trial. The defendant moved for an award of costs under Rule 68, and the judge subsequently changed the judgement in favor of the defendant on all charges and denied the defendant's motion for costs (see the discussion of Delta Air Lines, Inc. in Section 3). The Court of Appeals reversed the lower court's decision, stating that such use of discretion decreases the probability of settlement.

${ }^{24}$ Alternative specifications for the outside option lead to a similar characterization of the fee-shifting rule but complicate the analysis. See the discussion at the end of this section. 
and fee-shifting rule that achieves an upper bound on the settlement rate. In addition to establishing the Pareto frontier, this approach also has several independent interpretations. First, imagine that the litigants bargain in a decentralized fashion and the court commits to a fee-shifting rule. If we believe that bargaining is approximately interim efficient, and if the mechanism is robust to small perturbations in the bargaining environment, then the fee-shifting rule that maximizes the settlement rate will approximate the one that we derive. ${ }^{25}$ Second, imagine that the litigants may privately contract upon the allocation of legal costs but have no discretion over the court's award. One would expect to see private offer-based fee-shifting arrangements or contracts specifying the allocation of costs contingent upon $z$ and the pretrial activity. For example, the defendant might state: "My private information tells me that I don't owe you a cent. To help convince you of this, I promise to pay your fees in the event that this case goes to court and you receive a large award." Although this illustration makes the intuition clear, strictly speaking, this article would require that the litigants design the mechanism at the ex ante stage (before their types are realized).

The approach and techniques used here are similar to those used in Myerson and Satterthwaite's (1983) analysis of mechanisms for bilateral trade. However, the fee-shifting rule introduces an additional instrument which is analogous to an optimal auditing technology (Baron and Besanko, 1984), since the probability of a trial plays the same role as the probability of a costly audit. ${ }^{27}$ One difference from the optimal auditing literature is that two agents are being audited simultaneously, so a punishment for one agent corresponds to a reward for the other.

We assume that the distribution of the court's award, $h(z \mid x, y)$, satisfies the monotone likelihood ratio property (MLRP): Higher litigant types are associated with stronger cases. In particular, $(\partial h(z \mid x, y) / \partial x) / h(z \mid x, y)$ is increasing in $z$, and $(\partial h(z \mid x, y) / \partial y) / h(z \mid x, y)$ is decreasing in $z$. This condition has a simple interpretation: For any prior distribution over types, a high signal generates posterior beliefs in which the expectation of $x$ is higher and the expectation of $y$ is lower. Assuming that $E[z \mid \underline{x}, \bar{y}]-K>0$ would imply that the plaintiff would never strictly prefer to drop the case before trial.

If a plaintiff has true type $x$ and announces that his type is $\hat{x}$, then his expected payoff from participating in the mechanism is

$$
E_{Y}\left\{(1-p(\hat{x}, y)) S(\hat{x}, y)+p(\hat{x}, y) E_{Z}\left[z-C_{P}(\hat{x}, y, z) \mid x, y\right]\right\}
$$

Similarly, a defendant who has true type $y$ and announces $\hat{y}$ receives

$$
E_{X}\left\{-(1-p(x, \hat{y})) S(x, \hat{y})-p(x, \hat{y}) E_{z}\left[z+C_{D}(x, \hat{y}, z) \mid x, y\right]\right\}
$$

Let $V^{P}(\hat{x}, x)$ and $V^{D}(\hat{y}, y)$ denote the "rents" received by the plaintiff and defendant, respectively, defined as their expected payoffs less their payoffs from the outside option.

$$
\begin{aligned}
V^{P}(\hat{x}, x) & =E_{Y}\left\{(1-p(\hat{x}, y))\left[S(\hat{x}, y)-E_{Z}(z \mid x, y)\right]\right. \\
& \left.-p(\hat{x}, y) E_{Z}\left[C_{P}(\hat{x}, y, z) \mid x, y\right]\right\}+k_{P} .
\end{aligned}
$$

\footnotetext{
${ }^{25}$ It is not clear why the litigants should necessarily play a game that maximizes the probability of settlement or how the most "efficient" bargaining mechanism may be implemented as an equilibrium of a sequential game. Spulber (1990) verifies in a model without fee shifting that neither the "split-the-difference" game nor the "first-and-final offer" game implements the Pareto frontier.

${ }^{26}$ Donohue (1991) also discusses private incentives to contract around existing fee-shifting rules.

${ }^{27}$ Also see Mookherjee and Png (1989) and Border and Sobel (1987).
} 


$$
\begin{aligned}
V^{D}(\hat{y}, y) & =E_{X}\left\{-(1-p(x, \hat{y}))\left[S(x, \hat{y})-E_{Z}(z \mid x, y)\right]\right. \\
& \left.-p(x, \hat{y}) E_{Z}\left[C_{D}(x, \hat{y}, z) \mid x, y\right]\right\}+k_{D} .
\end{aligned}
$$

Interim individual rationality requires that the mechanism gives the plaintiff and defendant at least their status quo payoffs, so the rents in (8) and (9) must be greater than or equal to zero when the litigants announce their true types. Incentive compatibility requires that truth telling is always an optimal strategy, i.e., that a litigant's rents are maximized when he announces his true type. Under the assumption that the mechanism $\langle p, S, C\rangle$ is almost everywhere continuously differentiable (an assumption we will maintain throughout this analysis), it follows (see, for example, Guesnerie and Laffont (1984)) that the mechanism is incentive compatible if and only if

$$
\frac{d V^{P}}{d x}(x, x)=\left.\frac{\partial V^{P}(\hat{x}, x)}{\partial x}\right|_{\hat{x}=x}, \quad \frac{d V^{D}}{d y}(y, y)=\left.\frac{\partial V^{D}(\hat{y}, y)}{\partial y}\right|_{\hat{y}=y}
$$

and

$$
\left.\frac{\partial^{2} V^{P}(\hat{x}, x)}{\partial \hat{x} \partial x}\right|_{\hat{x}=x} \geq 0,\left.\quad \frac{\partial^{2} V^{D}(\hat{y}, y)}{\partial \hat{y} \partial y}\right|_{\hat{y}=y} \geq 0 .
$$

Equation (10) gives the first-order conditions, and (11) gives the second-order conditions for truth telling to be the optimal strategy. Differentiating the expressions in (8) and (9) enables us to write the first-order conditions as

$$
\begin{aligned}
& \frac{d V^{P}(x, x)}{d x}=\int_{Y} \int_{Z}\left\{-[1-p(x, y)] z-p(x, y) C_{P}(x, y, z)\right\} \frac{\partial h(z \mid x, y)}{\partial x} f_{Y}(y) d z d y \\
& \frac{d V^{D}(y, y)}{d y}=\int_{X} \int_{Z}\left\{[1-p(x, y)] z-p(x, y) C_{D}(x, y, z)\right\} \frac{\partial h(z \mid x, y)}{\partial y} f_{X}(x) d z d x .
\end{aligned}
$$

The litigants have a natural inclination to overstate their types. The plaintiff, for example, would like to convince the defendant that the damages are large in order to induce a more favorable settlement, and the defendant would like to convince the plaintiff that his level of care is high. For this reason, the mechanism must give positive rents to the lower types in order to induce truth telling. In the absence of fee shifting, incentive compatibility (12) implies that the rents will be decreasing in type. Fee shifting has the power to weaken these incentive-compatibility constraints: The rents need not decrease as fast, and the probability of a trial may consequently be reduced. It is interesting to note that since the rents given to the plaintiff are declining at a slower rate in the presence of fee shifting than under the American Rule, a plaintiff with a very weak case may not be able to exploit the pretrial negotiation to his advantage, and fee shifting may discourage lowmerit cases from being pursued.

If the court is very costly, then incentive compatibility and individual rationality are trivially satisfied by a mechanism that specifies that the case settles out of court for, say, one penny. ${ }^{28}$ The plaintiff is better off receiving a penny than going to trial and paying huge fees. When the costs are small, however, it is impossible for the litigants to resolve their dispute without the intervention of the legal system. In order to prove this general result (Proposition 1), we need the following lemma.

Lemma 1 . If the direct mechanism $\langle p, S, C\rangle$ is incentive compatible and individually rational, then

${ }^{28}$ If the court's sole objective were to maximize the settlement rate, it could do so by making the use of the court prohibitively expensive. The court presumably does not do this, because it is trading off the cost of providing an enforcement technology against other social goals, such as the provision of optimal penalties to deter negligent behavior. 


$$
\begin{aligned}
\int_{X} \int_{Y} \int_{Z}\{K[1- & p(x, y)]-[(1-p(x, y)) z \\
& \left.\left.+p(x, y) C_{P}(x, y, z)\right]\right\} \phi(x, y, z) h(z \mid x, y) f_{X}(x) f_{Y}(y) d z d y d x \geq 0,
\end{aligned}
$$

where

$$
\phi(x, y, z)=\frac{\partial h(z \mid x, y) / \partial x}{h(z \mid x, y)} \frac{F_{X}(x)}{f_{X}(x)}-\frac{\partial h(z \mid x, y) / \partial y}{h(z \mid x, y)} \frac{F_{Y}(y)}{f_{Y}(y)}
$$

Proof. See the Appendix.

Proposition 1. When $K$ is sufficiently small, no incentive compatible, individually rational mechanism exists in which the probability of going to court is zero.

Proof. Suppose not. Then there exists an incentive compatible, individually rational mechanism with $p(x, y)=0$ for all $x, y$. By Lemma 1 , we have $E_{X, Y, Z}[(K-z) \phi(x, y, z)] \geq 0$. Since MLRP implies first-order stochastic dominance, $E_{Z}[z \phi(x, y, z)]>0$ for all $x$ and $y$. Therefore, (13) is violated when $K$ is small. Q.E.D.

Unlike the results of Myerson and Satterthwaite (1983), breakdowns occur despite common knowledge that there exist gains from trade. Here, the litigants know that by settling they can save legal costs, while in the bilateral trade example with independent private values, the result holds only when the supports for the buyer's valuation and the seller's cost overlap. Furthermore, one-sided asymmetric information is sufficient to generate our result. (Samuelson (1984) has a similar result for bilateral trade with common values and one-sided incomplete information.)

We now characterize the incentive compatible, individually rational mechanism that minimizes the probability that the case will go to court. This mechanism is the solution to the following program:

$$
\begin{gathered}
\max _{\langle p, S, C\rangle}-\int_{X} \int_{Y} p(x, y) f_{X}(x) f_{Y}(y) d y d x . \\
\text { subject to } \\
V^{P}(x, x) \geq V^{P}(\hat{x}, x) \quad \forall x, \hat{x} \in[\underline{x}, \bar{x}] \\
V^{D}(y, y) \geq V^{D}(\hat{y}, y) \quad \forall y, \hat{y} \in[\underline{y}, \bar{y}] \\
V^{P}(x, x) \geq 0 \quad \forall x \in[\underline{x}, \bar{x}] \\
V^{D}(y, y) \geq 0 \quad \forall y \in[\underline{y}, \bar{y}] \\
p(x, y) \in[0,1] \quad \forall x \in[\underline{x}, \bar{x}], \quad \forall y \in[\underline{y}, \bar{y}] \\
C_{i}(x, y, z) \in[0, K] \quad i=P, D \\
C_{P}(x, y, z)+C_{D}(x, y, z)=K .
\end{gathered}
$$

Rather than solve this program directly, we will follow the approach of Myerson and Satterthwaite (1983) and relax the program by replacing the incentive-compatibility and individual rationality constraints with inequality (13) from Lemma 1.

$$
\max _{\langle p, C\rangle}-K \int_{X} \int_{Y} p(x, y) f_{X}(x) f_{Y}(y) d y d x
$$

subject to (13), (17), and (18).

The following Lemma gives conditions under which the solution to program (P2) is the solution to the original problem, (P1). In particular, if the solution to (P2) satisfies 
the second-order conditions in (11), and furthermore if the implied rents are nonincreasing in type, then it is also the solution of the unrelaxed program (P1).

Lemma 2. Suppose the functions $p(x, y), C_{P}(x, y, z)$, and $C_{D}(x, y, z)$ are such that (11) and (13) are satisfied. Furthermore, suppose that $V^{P}(x, x)$ and $V^{D}(y, y)$ are nonincreasing. Then there exists a transfer function $S(x, y)$, such that the mechanism $\langle p, S, C\rangle$ is incentive compatible and individually rational.

Proof. See the Appendix.

By specifying a Lagrange multiplier, $\lambda$, for the constraint (13), (P2) may be solved by pointwise maximization. It follows from Lemma 1 that the constraint must bind when $K$ is sufficiently small (otherwise, $p(x, y)=0$ for all types and (13) is violated). The following proposition characterizes the mechanism that solves the relaxed program ( $\mathrm{P} 2)$. The simple proof, which will not be presented, involves pointwise maximization.

Proposition 2. If $K$ is sufficiently small, then the solution to the relaxed program (P2) is characterized by

$$
\begin{aligned}
& p(x, y)= \begin{cases}1 & \text { if } E_{Z}\left\{\left[z-C_{P}(x, y, z)\right] \phi(x, y, z)\right\}>\frac{1}{\lambda}+K \\
0 & \text { otherwise. }\end{cases} \\
& \text { If } p(x, y) \phi(x, y, z) \leq 0, \text { then } C_{P}(x, y, z)=K, C_{D}(x, y, z)=0 . \\
& \text { If } p(x, y) \phi(x, y, z)>0, \text { then } C_{P}(x, y, z)=0, C_{D}(x, y, z)=K .
\end{aligned}
$$

Furthermore, if this mechanism has the following properties:

(i) The second-order conditions (11) are satisfied; and

(ii) $V^{P}(\bullet)$ and $V^{D}(\bullet)$ are nonincreasing in $x$ and $y$, respectively,

then the solution to $(\mathrm{P} 2)$ is also the solution to $(\mathrm{P} 1)$.

The solution to the relaxed program given in Proposition 2 has an interesting feature: Given the litigant's pretrial announcements $\hat{x}$ and $\hat{y}$, the court establishes a cutoff value for its signal which we denote by $z^{*}(\hat{x}, \hat{y})$, such that when $z$ exceeds this value, the defendant bears the plaintiff's costs, and when $z$ is below this value, the plaintiff bears the defendant's costs. This property follows immediately from the MLRP for $h(z \mid x, y)$, which implies that $\phi(x, y, z)$ is increasing in $z$. It is also quite intuitive: Under MLRP, high values for $z$ correspond to high $x$ 's and low $y$ 's. When $z$ is high relative to the litigant's announcements, the court treats the situation as if the defendant lied and underreported his type, while if $z$ is low relative to the announcements, the court treats the plaintiff as a liar and forces him to bear the entire cost of litigation. We are dealing with truth-telling mechanisms, so no lying occurs in equilibrium - the court commits to behave in this way because of the helpful incentive properties it provides.

In this general specification, it is difficult to characterize how the cutoff $z^{*}(x, y)$ changes as $x$ and $y$ change. Furthermore, it is difficult to verify that the solution to (P2) is also the solution to (P1). If $z$ is normally distributed, however, then a very appealing rule emerges: The cutoff for the signal defined by Proposition 2 is simply the mean of the distribution conditional upon the announcements of the players, $m(\hat{x}, \hat{y})$. Intuitively, given the statements made by the litigants before the trial, the court forms expectations about the true level of damages. If the observed damages exceed this expectation, then the defendant is penalized, and if the observed damages fall short of this expectation, the plaintiff is penalized. It is also relatively straightforward to check conditions (i) and (ii) of Proposition 2 for this specification. 
Proposition 3. Suppose $z$ is normally distributed with mean $m(x, y)$ and variance $\sigma^{2}$ and $K$ is not too large. Furthermore, suppose $m(x, y)$ is a differentiable function with partial derivatives $\partial m(\bullet) / \partial x>0$ and $\partial m(\bullet) / \partial y<0$. Then the solution to (P2) specifies that the defendant bears the plaintiff's costs when $z \geq m(\hat{x}, \hat{y})$, and the plaintiff bears the defendant's costs when $z<m(\hat{x}, \hat{y})$. Furthermore, if this mechanism has the following properties:

(i) $p(x, y)$ is weakly increasing in $x$ and $y$; and

(ii) $V^{P}(\bullet)$ and $V^{D}(\bullet)$ are nonincreasing in $x$ and $y$, respectively,

then the solution to (P2) is also the solution to the original program (P1).

Proof. See the Appendix.

The solution to (P2) corresponds to the solution to (P1) under two conditions. First, $p(x, y)$ is nondecreasing in its arguments. The probability of going to trial serves as an instrument for inducing truth telling; when a litigant exaggerates the strength of his case, the likelihood of going to trial should increase, along with the likelihood of bearing his opponent's costs. This first condition will be satisfied when the sum of the inverse hazard rates weighted by the partial derivatives of the mean function is monotonic in its arguments (see equation (A10) in the Appendix). (If this condition is not satisfied, then, as is typical in the literature, some bunching will arise.)

The second condition in Proposition 3 is that the rents are nonincreasing in their arguments. Since each litigant has a natural inclination to exaggerate the strength of his case, the mechanism should give rents to the weaker types to induce truth telling. This condition will be satisfied by the solution to (P2) when the expected (interim) probability of a trial is not too large for every litigant type (see equations (A12) and (A13) in the Appendix). Intuitively, if a defendant believes that a trial is highly likely, then, taking our fee-shifting rule as given, he has an incentive to understate rather than overstate his type. By understating his type, the defendant makes it look as if the plaintiff lied, and hence the defendant is less likely to bear the costs of litigation. This presents a problem, for it may no longer be true that individual rationality will only bind at the top. (Our solution technique assumed that these constraints only bound at the top.) A more general analysis of this problem would have to allow for the possibility that the individual rationality constraints bind in the interior of the supports.

In the following functional specification, we may easily find conditions on the parameter values such that both conditions are satisfied, i.e., that Proposition 3 fully characterizes the solution to program (P1). Suppose $m(x, y)=n+x-y$, where $x$ and $y$ are uniformly distributed on [0,1] and $n$ is an arbitrary constant. The solution to (P2) is characterized by

$$
\begin{aligned}
& p(x, y)= \begin{cases}1 & \text { if } x+y \geq \frac{1 / \lambda+K}{1+K /(\sqrt{2 \pi}) \sigma}=\beta \\
0 & \text { otherwise. }\end{cases} \\
& \text { If } z \leq c+x-y \text {, then } C_{P}(x, y, z)=K, C_{D}(x, y, z)=0 \text {. } \\
& \text { If } z>c+x-y \text {, then } C_{P}(x, y, z)=0, C_{D}(x, y, z)=K \text {. }
\end{aligned}
$$

The value for the Lagrange multiplier, $\lambda$, may be found by evaluating the constraint (13) when it holds with equality. After some manipulation, we have $\lambda$ implicitly given by

$$
K\left[12 \beta-6-3 \beta^{2}+\frac{6}{\sqrt{2 \pi} \sigma}\right]+\left[1+\frac{K}{\sqrt{2 \pi} \sigma}\right]\left[2-6 \beta^{2}+2 \beta^{3}\right]=0
$$

where $\beta$ is defined in (19). 
Totally differentiating (20), we find that if $K$ falls or $\sigma$ rises (the signal becomes less accurate), then $\beta$ falls (the likelihood of settlement falls). The intuition for the first effect is straightforward: When $K$ decreases (i.e., the gains from settling out of court are smaller), it becomes more difficult to design a mechanism for which settlement is very likely. The role of $\sigma$, the standard deviation, is more subtle. When $\sigma$ increases, the distribution of $z$ is more dispersed, and the marginal cost from overannouncing in the direct mechanism is reduced. As a consequence, the fee-shifting rule becomes less powerful in inducing settlement and the likelihood of settlement falls.

Condition (i) of Proposition 3 is satisfied by the mechanism in (19), since $p(x, y)$ is monotonic in $x$ and $y$. We need to find conditions on the parameter values to satisfy condition (ii), that the rents are nonincreasing in type. Using (A12) and (A13) from the Appendix, this condition is given by

$$
\beta \geq 2-\frac{1}{1+\frac{K}{\sqrt{2 \pi} \sigma}} .
$$

For this to be true, we need a mechanism in which the probability of going to trial is not too large. In other words, there must be a big enough chance that even the strongest case settles out of court. Intuitively, $K$ cannot be too small: In the extreme, if $K=0$, all cases proceed to court and monotonicity is violated.

Proposition 4. Suppose $z$ is normally distributed with mean $m(x, y)=n+x-y$ and variance $\sigma^{2}$, where $x$ and $y$ are uniformly distributed on [0,1]. For each $K \in(2 / 3,1]$, there exists $\sigma^{*}(K)$, such that for all $\sigma \geq \sigma^{*}(K)$, the mechanism in (19) solves both the relaxed program $(\mathrm{P} 2)$ and the unrelaxed program $(\mathrm{P} 1)$.

Proof. Given $K$ and $\sigma$, the corresponding $\beta$ defined by (20) must satisfy (21). When $\sigma \rightarrow \infty$, inequality (21) becomes $\beta \geq 1$, and evaluating (20), we have that if $K=2 / 3$, then $\beta=1$ and if $K=1$, then $\beta=2$. By continuity, for $\sigma$ sufficiently large, every $K \in(2 / 3,1)$ satisfies $\beta \in[1,2]$. Furthermore, when $K=1, \beta=2$ for all $\sigma>0$. Q.E.D.

To illustrate, suppose $K=.7$ and $\sigma=.35$. From (19) and (20), we find that $\beta=1.5$ and $\lambda=.5$, and this satisfies condition (21). These parameter values correspond to a litigation rate of $14 \%$. Under the American Rule, the standard deviation is irrelevant for the litigants, since they only care about the expected value of $z$. The solution for $\beta$ in this case is obtained from (20) by setting all of the terms involving $\sigma$ equal to zero. For the very same values, the American Rule would lead to $\beta=1.05$, or a litigation rate of $45 \%$.

These results suggest that fee-shifting rules that are based upon the litigant's pretrial activities are valuable in relaxing incentive-compatibility constraints when the court's award is drawn from a "smooth" distribution. Suppose, on the other hand, that the court's signal takes on just two values (so the litigant's private information impacts the probability of each of these signals). It is straightforward to derive the fee-shifting rule using techniques analogous to those presented here. When $z$ is either "high" or "low," the fee-shifting rule simply specifies that when $z$ is high, the defendant bears the costs, and when $z$ is low, the plaintiff bears the costs. Notice that this rule is not inherently offer-based (because it does not depend upon the pretrial announcements), and for the win-lose case, it is simply the English Rule.

In the mechanism-design analysis, the outside option was exogenously specified to be the American Rule. One could also experiment with other specifications. For example, the outside option could punish a deviator by forcing him to bear his opponent's costs. Alternatively, the outside option could itself be a fee-shifting rule, or a rule for allocating 
costs that is independent of the litigants' pretrial announcements (such as the English Rule). ${ }^{29}$ However, the nature of the fee-shifting rule characterized in the propositions is largely independent of the specification of the outside option.

As a mechanism-design exercise, one might design the outside option to increase the rate of settlement. Suppose that one restricted attention to fee-shifting rules that depend only upon the court's signal, $z$. The following outside-option specification implies that the litigants outside-option payoffs increase less rapidly in their types and serves to relax the incentive-compatibility constraints: When $z$ is sufficiently high, the plaintiff bears all of the costs, and when $z$ is low, the defendant bears all of them. For example, in the winlose case, the outside-option fee-shifting rule that maximizes the settlement rate has the winner bear the loser's costs (the reverse of the English Rule). Moreover, if the mechanism were restricted to specify the same fee-shifting rule for both the outside option and the standard rule, then this "reverse English Rule" would, in fact, dominate as the rule that maximizes the settlement rate.

This discussion raises a general caveat about the mechanism-design approach as compared to the extensive-form game approach. When liability is in dispute but the damages are known, the mechanism-design technique with the outside option exogenously specified suggests that the English Rule for shifting fees enhances settlement. However, recall that the standard extensive-form games (my own included) suggest that the English Rule discourages settlement. These results may be partially reconciled by noting that, in reality, the English Rule is applied whether or not settlement offers are made, and hence the English Rule serves as the outside option in bargaining ${ }^{30}$ However, the mechanism-design exercise assumed that the American Rule served as the outside option, and so the two models are not directly comparable.

While the mechanism-design approach yields insights not offered by the extensiveform game approach, the intuition for these results is much stronger when only damages are in dispute. As noted above, when only liability is disputed, the mechanism that emerges is independent of the pretrial announcements. A complete reconciliation of the two approaches might be obtained from a broader analysis of extensive-form games in which the outside option of the bargaining game is more fully explored. However, it is not clear that such extensions would yield any new guidelines for policy makers.

\section{Conclusions}

- Fee-shifting rules that depend upon the pretrial activity in addition to the trial's outcome can serve as powerful policy instruments. It was illustrated both in the context of an extensive-form bargaining game and in a direct-revelation mechanism that when the court's award is drawn from a continuous distribution, the offer-based fee-shifting rules can encourage truth telling and thereby facilitate settlement. Despite the differences in abstraction between the two approaches, many of the insights are similar. Litigants may be deterred from exaggerating their claims for two reasons: "Exaggeration" (1) increases the likelihood of a trial and (2) increases the expected costs contingent upon reaching trial.

${ }^{29}$ If in the outside option the plaintiff is entitled to no recovery at all, then it is trivial to design a mechanism with a perfect settlement rate by setting the transfer equal to zero. If either the plaintiff or the defendant opted out, the court would award nothing to the plaintiff, and litigation costs would be incurred needlessly.

${ }^{30}$ Note that in the extensive-form game presented in Section 3, I did not explore the possibility for the plaintiff to "opt out." The defendant, of course, is always willing to make an offer, because by doing so, the plaintiff's fees may be shifted. (This would be true in a two-sided version of Rule 68 as well, because making an offer can only serve to improve the payoff of the offerer at trial.) However, a plaintiff who anticipates rejecting the Rule 68 offer would, strictly speaking, prefer to opt for a trial under the American Rule. However, it is clear that Rule 68 treats a litigant's desire to opt out by "refusing to hear an offer" as equivalent to rejecting the offer. 
Exaggeration can either be thought of in the context of settlement negotiations (i.e., making offers and deciding whether to accept or reject them) or in the context of direct-revelation mechanisms.

There are several differences between the mechanism-design characterization and actual fee-shifting rules. First, actual two-sided rules (such as Senate Bill 640 and California Code of Civil Procedure 998) feature an intermediate range between the offers for which the American Rule prevails, while the direct-revelation mechanism features a single cutoff. A possible reason for this difference is that, in reality, settlement offers serve as rules of thumb for the court. It may be difficult for the court to tailor a precise cutoff on a caseby-case basis, especially since it may have very imprecise knowledge of the underlying parameters and distributions. Second, many offer-based rules do not include attorneys' fees in the definition of costs. Third, many rules remain one-sided. The theory presented here predicts that broadening the definition of costs to include attorneys' fees and extending the rules to offers made by either litigant will increase their effectiveness in encouraging settlement.

Many other issues are important in the fee-shifting debate but are beyond the scope of this analysis. If the primary goal of the court system is to improve social welfare, then the court will be concerned with a host of issues not addressed here, including the defendant's incentives to take precautions $e x$ ante, the plaintiff's incentives to bring suit, and the possibility of nuisance litigation. One direction for further research would be to incorporate these concerns into the design of direct-revelation mechanisms. However, the complexity of administering and enforcing sophisticated mechanisms may, in practice, limit their use. Indeed, the methods used in our tort system for determining damage awards tend to be quite primitive; rules in which the victim is simply awarded the true value of his damages are typical. The analysis presented here is in this spirit: Offer-based feeshifting rules may be viewed as natural instruments for encouraging settlement, while the underlying penalty structure may be viewed as the primary instrument for inducing care.

\section{Appendix}

- Proofs of Lemmas 1 and 2 and Proposition 3 follow.

Proof of Lemma 1. Integrating the first-order conditions (12) gives

$$
\begin{gathered}
V^{P}(x, x)=V^{P}(\bar{x}, \bar{x})+\int_{x}^{\bar{x}} \int_{Y} \int_{Z}\left\{[1-p(t, y)] z+p(t, y) C_{P}(t, y, z)\right\} \frac{\partial h(z \mid t, y)}{\partial t} f_{Y}(y) d z d y d t \\
V^{D}(y, y)=V^{D}(\bar{y}, \bar{y})+\int_{y}^{\bar{y}} \int_{X} \int_{Z}\left\{[1-p(x, r)] z-p(x, r) C_{D}(x, r, z)\right\} \frac{\partial h(z \mid x, r)}{\partial r} f_{X}(x) d z d x d r .
\end{gathered}
$$

Taking expectations over $x$ and $y$, respectively, and using the facts that $C_{P}(x, y, z)+C_{D}(x, y, z)=K$ and that the integral of $\partial h(z \mid x, y) / \partial y$ over $z$ equals 0 , the total expected rents given to the litigants may be written as

$$
\begin{aligned}
& V^{P}(\bar{x}, \bar{x})+V^{D}(\bar{y}, \bar{y})+\int_{X} \int_{Y} \int_{Z}\{[1-p(x, y)] z \\
& \left.\quad+p(x, y) C_{p}(x, y, z)\right\} \phi(x, y, z) h(z \mid x, y) f_{X}(x) f_{Y}(y) d z d y d x,
\end{aligned}
$$

where $\phi(x, y, z)$ is given in (14). Using the definitions of $V^{P}(x, x)$ and $V^{D}(y, y)$ in (8) and (9), an alternative expression for the total rents is

$$
K \int_{X} \int_{Y} \int_{Z}[1-p(x, y)] h(z \mid x, y) f_{X}(x) f_{Y}(y) d z d y d x .
$$

This is the total expected costs savings from participating in the mechanism. These expressions must be equal, so we have

$$
\begin{aligned}
V^{P}(\bar{x}, \bar{x})+V^{D}(\bar{y}, \bar{y}) & =\int_{X} \int_{Y} \int_{Z}\{K[1-p(x, y)]-[(1-p(x, y)) z \\
& \left.\left.+p(x, y) C_{P}(x, y, z)\right] \phi(x, y, z)\right\} h(z \mid x, y) f_{X}(x) f_{Y}(y) d z d y d x
\end{aligned}
$$

Individual rationality for the highest types completes the proof. Q.E.D. 
Proof of Lemma 2. Given $p(x, y), C_{P}(x, y, z)$ and $C_{D}(x, y, z)$, the following transfer function will satisfy individual rationality and incentive compatibility when the conditions stated in the Lemma are satisfied:

$$
\begin{aligned}
(1-p(x, y)) S(x, y) & =-\int_{x}^{\bar{x}} \frac{d V^{P}(t, t)}{d t} d t+\int_{y}^{\bar{s}} \frac{d V^{D}(r, r)}{d r} d r \\
& +E_{Z}\left\{[1-p(x, y)] z+p(x, y) C_{P}(x, z, y)\right\}+E_{X}\{K[1-p(x, y)]\}+\text { constant. }
\end{aligned}
$$

The first two terms on the right-hand side of the equation are as given in (12).

To establish this result, first substitute the transfer function into the definition of the defendant's rents, (9), and let the constant in (A5) be such that individual rationality binds for the highest type of defendant. When the inequality in (13) holds, we easily establish individual rationality for the highest type of plaintiff. The supposition that $V^{P}(x, x)$ and $V^{D}(y, y)$ are nonincreasing everywhere allows us to conclude that no type incurs negative rents. Q.E.D.

Proof of Proposition 3. $\phi(x, y, z)$ can be written

$$
\phi(x, y, z)=\frac{[z-m(x, y)]}{\sigma^{2}}\left\{\frac{\partial m(x, y)}{\partial x} \frac{F_{X}(x)}{f_{X}(x)}-\frac{\partial m(x, y)}{\partial y} \frac{F_{Y}(y)}{f_{Y}(y)}\right\} .
$$

From Proposition 1 , it is clear that if $p(x, y)>0$, then $C_{P}(x, y, z)=K$ if and only if $\phi(x, y, z) \leq 0$. Since $\partial m(\bullet) / \partial x>0$ and $\partial m(\bullet) / \partial y<0$ and $f_{X}(x)$ and $f_{Y}(y)$ are strictly positive on their supports, (A6) implies that $\phi(x, y, z)<0$ if and only if $z-m(x, y)<0$.

Substituting $\phi(x, y, z)$ into the first expression in Proposition 2 gives $p(x, y)=1$ if and only if

$$
\int_{z}\left[z-C_{P}(x, y, z)\right][z-m(x, y)] h(z \mid x, y) d z \geq \alpha(x, y)\left(\frac{1}{\lambda}+K\right),
$$

where

$$
\alpha(x, y)=\sigma^{2}\left[\frac{\partial m(x, y)}{\partial x} \frac{F_{X}(x)}{f_{X}(x)}-\frac{\partial m(x, y)}{\partial y} \frac{F_{Y}(y)}{f_{Y}(y)}\right]^{-1} .
$$

Using the form of $C_{P}(x, y, z)$ defined in Proposition 3, we rewrite the left-hand side of (A7)

$$
\int_{Z} z[z-m(x, y)] h(z \mid x, y) d z-K \int_{-\infty}^{m(x, y)}[z-m(x, y)] h(z \mid x, y) d z .
$$

The first term equals $\sigma^{2}$, and the second equals $K \sigma / \sqrt{2 \pi}$, and this gives us that

$$
p(x, y)=1 \leftrightarrow 1+\frac{K}{\sqrt{2 \pi} \sigma} \geq \frac{1 / \lambda+K}{\left[\frac{\partial m(x, y)}{\partial x} \frac{F_{X}(x)}{f_{X}(x)}-\frac{\partial m(x, y)}{\partial y} \frac{F_{Y}(y)}{f_{Y}(y)}\right]} .
$$

It remains to be shown that the mechanism satisfies the second-order conditions given in (11). One can do this directly for the plaintiff by evaluating

$$
\operatorname{Lim}_{\hat{x} \rightarrow x} E_{Y}\left\{\left[\frac{p(\hat{x}, y)-p(x, y)}{\hat{x}-x}\right] \int_{Z} z \frac{\partial h(\bullet)}{\partial x} d z-\frac{K}{\hat{x}-x}\left[p(\hat{x}, y) \int_{-\infty}^{m(\hat{x}, y)} \frac{\partial h(\bullet)}{\partial x} d z-p(x, y) \int_{-\infty}^{m(x, y)} \frac{\partial h(\bullet)}{\partial x} d z\right]\right\} .
$$

Using the supposition (i) in the proposition and MLRP establishes that this expression is positive. Similarly, the second-order condition holds for the defendant. The derivatives of the rents may be derived from (12):

$$
\frac{d V^{P}(x, x)}{d x}=E_{Y}\left\{\frac{\partial m(x, y)}{\partial x}\left[-1+p(x, y)\left(1+\frac{K}{\sqrt{2 \pi} \sigma}\right)\right]\right\}
$$

and

$$
\frac{d V^{D}(y, y)}{d y}=E_{X}\left\{-\frac{\partial m(x, y)}{\partial y}\left[-1+p(x, y)\left(1+\frac{K}{\sqrt{2 \pi} \sigma}\right)\right]\right\}
$$




\section{References}

BARON, D.P. AND BESANKo, D. "Regulation, Asymmetric Information and Auditing." RAND Journal of Economics, Vol. 15 (1984), pp. 447-470.

Bевсник, L.A. "Litigation and Settlement Under Imperfect Information." RAND Journal of Economics, Vol. 15 (1984), pp. 404-415.

BERnSTEIN, L. "Understanding the Limits of Court-Connected ADR: A Critique of Federal Court-Annexed Arbitration Programs.” University of Pennsylvania Law Review, Vol. 141 (1993), pp. 2169-2259.

Border, K.C. AND Sobel, J. "Samurai Accountant: A Theory of Auditing and Plunder." Review of Economic Studies, Vol. 54 (1987), pp. 524-540.

Braeutigam, R., Owen, B., And Panzar, J. "An Economic Analysis of Alternative Fee Shifting Systems." Law and Contemporary Problems, Vol. 47 (1984), pp. 173-185.

CArroll, S.J. Jury Awards and Prejudgment Interest in Tort Cases. Santa Monica, Calif.: RAND, The Institute for Civil Justice, N-1994-ICJ, 1983.

Cooter, R., Marks, S., And Mnookin, R. "Bargaining in the Shadow of the Law: A Testable Model of Strategic Behavior." Journal of Legal Studies, Vol. 11 (1982), pp. 225-251.

Daughety, A.F. And Reinganum, J.F. "Keeping Society in the Dark: On the Admissibility of Pretrial Negotiations as Evidence in Court.” Working Paper no. 91-24, University of Iowa, 1991. Revised March 1994.

Donohue, J.J. III. "Opting for the British Rule, or if Posner and Shavell Can't Remember the Coase Theorem, Who Will?" Harvard Law Review, Vol. 104 (1991), pp. 1093-1119.

Fournier, G.M. AND ZuehlKe, T.W. "Litigation and Settlement: An Empirical Approach." Review of Economics and Statistics, Vol. 71 (1989), pp. 189-195.

Gould, J.P. “The Economics of Legal Conflicts.” Journal of Legal Studies, Vol. 2 (1973), pp. 279-300.

Guesnerie, R. AND LAFFont, J-J. "A Complete Solution to a Class of Principal-Agent Problems with an Application to the Control of a Self-Managed Firm." Journal of Public Economics, Vol. 25 (1984), pp. 329369.

Hause, J.C. “Indemnity, Settlement, and Litigation, or I'll Be Suing You.” Journal of Legal Studies, Vol. 18 (1989), pp. 157-179.

KATZ, A. “Measuring the Demand for Litigation: Is the English Rule Really Cheaper?” Journal of Law, Economics and Organization, Vol. 3 (1987), pp. 143-176.

LANDES, W.M. “An Economic Analysis of the Courts.” Journal of Law and Economics, Vol. 14 (1971), pp. $61-107$.

LeubSDORF, J. "Toward a History of the American Rule on Attorney Fee Recovery." Law and Contemporary Problems, Vol. 47 (1984), pp. 9-36.

Lewis, T.R. And SAPPIngton, D.E.M. "Countervailing Incentives in Agency Problems." Journal of Economic Theory, Vol. 49 (1989), pp. 294-313.

MACEY, J.R. “Judicial Preference, Public Choice, and the Rules of Procedure.” Journal of Legal Studies, Vol. 23 (1994) pp. 627-646.

Miller, G.P. “An Economic Analysis of Rule 68.” Journal of Legal Studies, Vol. 15 (1986), pp. 93-125.

MOOKHERJEe, D. AND PNG, I. “Optimal Auditing, Insurance, and Redistribution.” Quarterly Journal of Economics, Vol. 104 (1989), pp. 399-415.

Myerson, R.B. "Incentive Compatibility and the Bargaining Problem." Econometrica, Vol. 47 (1979), pp. $61-73$.

- AND SATterthwaite, M.A. "Efficient Mechanisms for Bilateral Trading." Journal of Economic Theory, Vol. 29 (1983), pp. 265-281.

NalebufF, B. "Credible Pretrial Negotiation." RAND Journal of Economics, Vol. 18 (1987), pp. 198-210.

PfEnNigstorf, W. "The European Experience with Attorney Fee-Shifting." Law and Contemporary Problems, Vol. 47 (1984) pp. 37-124.

Posner, R.A. “An Economic Approach to Legal Procedure and Judicial Administration." Journal of Legal Studies, Vol. 2 (1973), pp. 399-458.

ReInganum, J.F. AND WiLDE, L.L. "Settlement, Litigation, and the Allocation of Litigation Costs." RAND Journal of Economics, Vol. 17 (1986), pp. 557-566.

SAMUELSON, W.F. “Bargaining under Asymmetric Information.” Econometrica, Vol. 52 (1984), pp. 995-1005.

SCHWARZER, W.W. "Fee-Shifting Offers of Judgement-An Approach to Reducing the Cost of Litigation." Judicature, Vol. 76 (1992), pp. 147-153.

SCHWEIZER, U. "Litigation and Settlement Under Two-Sided Incomplete Information." Review of Economic Studies, Vol. 56 (1989), pp. 163-178.

Shavell, S. "Suit, Settlement, and Trial: A Theoretical Analysis under Alternative Methods for the Allocation of Legal Costs." Journal of Legal Studies, Vol. 11 (1982), pp. 55-81.

SIMON, R.D. JR. “The Riddle of Rule 68." George Washington Law Review, Vol. 54 (1985), pp. 1-89.

SNyder, E.A. AND Hughes, J.W. "The English Rule for Allocating Legal Costs: Evidence Confronts Theory." Journal of Law, Economics and Organization, Vol. 6 (1990), pp. 345-380.

SPIER, K.E. “Three Essays on Dispute Resolution and Incomplete Contracts.” Ph.D. dissertation, Department of Economics, MIT, 1989. 


\section{4 / THE RAND JOURNAL OF ECONOMICS}

“The Dynamics of Pretrial Negotiation." Review of Economic Studies, Vol. 59 (1992a), pp. 93-108. "Pretrial Bargaining and Fee-Shifting Mechanisms: A Theoretical Foundation for Rule 68." Harvard Law School Program in Law and Economics Discussion Paper no. 113, 1992b.

Spulber, D. "Contingent Damages and Settlement Bargaining." Mimeo, J.L. Kellogg Graduate School of Management, Northwestern University, 1990. 